\title{
Real-time switching thirteen-level modified CHB-multilevel inverter using artificial neural network technique based on selective harmonic elimination
}

\author{
Moataz M. A. Alakkad, Zulhani Rasin, Mohammed Rasheed, Wahidah Abd Halim, Rosli Omar \\ Centre for Robotics and Industrial Automation (CeRIA), Universiti Teknikal Malaysia Melaka, Malaysia
}

\begin{tabular}{|c|c|}
\hline Article Info & ABSTRACT \\
\hline Article history: & \multirow{10}{*}{$\begin{array}{l}\text { Recently, global research is giving more attention to the renewable energy } \\
\text { sources due to its sustainability and environmentally friendly nature. The } \\
\text { necessity of DC to AC conversion to integrate these sources to the well } \\
\text { established AC power system create a significant development of multi-level } \\
\text { inverter with its advantages of operating at higher rating system with lower } \\
\text { component rating as well as better harmonics performance at it output voltage } \\
\text { and current. In this research paper, a modified topology of CHB-MLI to } \\
\text { provide 13-level output AC waveform is proposed based on the SHE-PWM } \\
\text { strategy using the ANN optimization technique. The system modeling is done } \\
\text { with Matlab Simulink software and verification are carried out by both } \\
\text { simulation and experiment. Results show that the ANN technique able to } \\
\text { reduce the THD significantly as the level of waveform is increased as low as } \\
\text { 5.16\% THD for the 13-level output voltage. Results from the experiment } \\
\text { shows a good agreement with the simulation, thus verifying the effectiveness } \\
\text { of the proposed ANN technique as an optimization method. }\end{array}$} \\
\hline Received May 4, 2020 & \\
\hline Revised Jul 25, 2020 & \\
\hline Accepted Aug 2, 2020 & \\
\hline Keywords: & \\
\hline Artificial intelligence & \\
\hline Cascaded H-bridge & \\
\hline Harmonics optimization & \\
\hline Multilevel inverter & \\
\hline Neural network & \\
\hline
\end{tabular}

Copyright (C) 2020 Institute of Advanced Engineering and Science. All rights reserved.

\section{Corresponding Author:}

Moataz M.A. Alakkad,

Power Electronics and Drives Research Laboratory,

Centre for Robotics and Industrial Automation (CeRIA),

Universiti Teknikal Malaysia Melaka (UTeM),

Hang Tuah Jaya, 76100 Durian Tunggal, Melaka, Malaysia.

Email: moatazmoneer77@gmail.com

\section{INTRODUCTION}

A multilevel inverter is a multiple installation of power electronic circuits that can produce alternating voltage-current (AC) waveform as an output from a direct current (DC) sources. Nowadays, the renewable energy sources such as photovoltaic (PV), wind and water turbines are significantly becoming important alternative power sources due to its sustainability and environmentally friendly nature [1]. Majority of these renewable sources produce a DC power waveform as an output which are not suitable for the power transmission, distribution and utilization purposes. Based on that, the produced DC power should be firstly converted into an $\mathrm{AC}$ power waveform and that can be realized by using a multilevel inverter (MLI) circuit [2-5]. In general, the building structure of the MLI can be classified into three main topologies based on the principle structure, known as flying capacitor MLI (FC-MLI), diode-clamped MLI (DC-MLI), and finally the cascaded h-bridge MLI (CHB-MLI) which is the most popular and more reliable.

The CHB-MLI topology consists of number of cells connected in series throughout the load, where for the conventional structure of CHB-MLI, each of cell uses four switches to produce three level output voltage for each of cell [6]. Several modulation methods have been proposed in order to eliminate the harmonics at the output voltage and current waveform such as the pulse width modulation (PWM) which considered as a high switching frequency strategy which includes the sinusoidal PWM (SPWM) and the space vector PWM (SVPWM). On the other side, the selective harmonic elimination PWM (SHE-PWM) method considered as a 
fundamental switching frequency strategy which shown to have several advantages, as it is the space vector control (SVC) [7[9]. In fact, by using the SHE-PWM strategy, a complex transcendental non-linear equation is found as result that must be solved, which is difficult to be solved by using simple methods. However, this equation can be solved by applying an iterative control method such as the newton-raphson (NR), particle swarm optimization (PSO), firefly algorithm (FFA) and artificial neural network (ANN). Optimization technique is necessary in order to identify and calculate the specific switching angles to provide a lower total harmonic distortion (THD) at the output waveform thus a smoother waveform which is directly proportional to the overall power efficiency of the system [10-11]. Basically, the THD can be defined as the ratio between the high harmonic components and low harmonic component as in the following (1) where $a_{n}$ are the high harmonic components and $a_{1}$ is the low harmonic component [12].

$$
T H D=\frac{\sum_{n=1,3,5 \ldots}^{\infty}\left(a_{n}\right)}{a_{1}}
$$

\section{MODIFIED CHB-MLI THIRTEEN-LEVEL CONFIGURATION}

As mentioned previously, the universal CHB-MLI topology includes a number of cells block where each one produces three level as an output by using four switching devices known as H-bridge diode-clamped switched circuit. Each of the cell is supplied by a separate DC source unit. The universal CHB-MLI then have been improved in which additional switch is added to each cell to create five switching devices in order to produce five levels output waveform [13]. Four switching devices are connected in H-bridge connection form and one switch as mutual switching device connected at the midpoint of a capacitor bank consisting of two balanced capacitance that supplied by input DC source as shown in Figure 1. As a result, the cell alone can produce five level of voltages of $\left(+V_{d c},+\frac{1}{2} V_{d c}\right.$, zero, $\left.-\frac{1}{2} V_{d c},-V_{d c}\right)$ [14]. Figure 2 shows the block diagram of the proposed modified CHB-MLI cell.

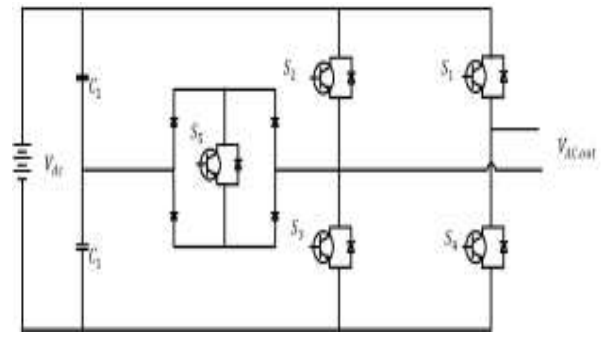

Figure 1. One of cell for multi-level CHB-MLI

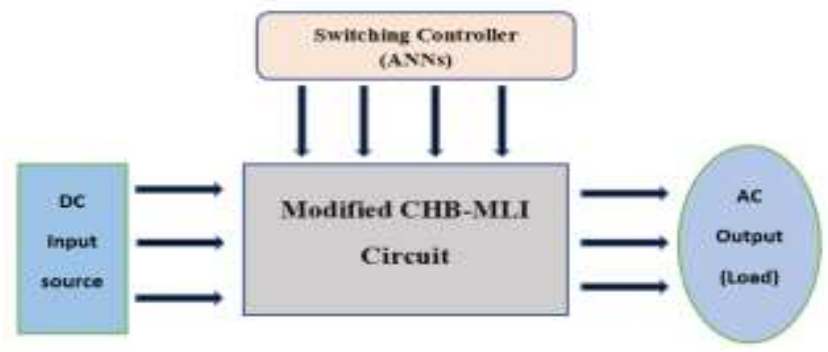

Figure 2. Block diagram of the proposed modified CHB-MLI cell

In this research paper, a thirteen-level modified structure CHB-MLI are proposed, which is formed by connecting three modified cell blocks in series connection method as shown in Figure 3. This structure of connection are able to generate 13-stepped level over one cycle of output voltage waveform as shown in Figure 4 by using switching behaviour as shown in Table 1. The Figure 1 clarifies that in this structure of 13-level MLI, the six switching angles must be calculated initially and they are all must be less or equal to $90^{\circ}$ and above of zero $\left(0<\theta_{1}<\theta_{2}<\theta_{3}<\theta_{4}<\frac{\pi}{2}\right)$ [15]. The total voltage at output side of MLI should be the summation of whole the cells output voltages which is approximately equal the total of input DC voltage source for all cells [16]. Therefore, the thirteen level CHB-MLI can generate an output voltage as below, 
$V_{\text {out }}=V_{d c 1}+V_{d c 2}+V_{d c 3}$

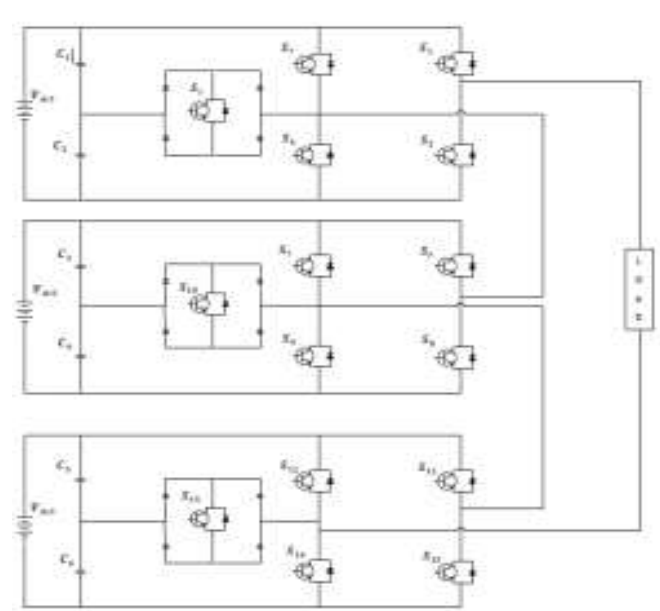

Figure 3. Modified thirteen-level CHB-MLI circuit

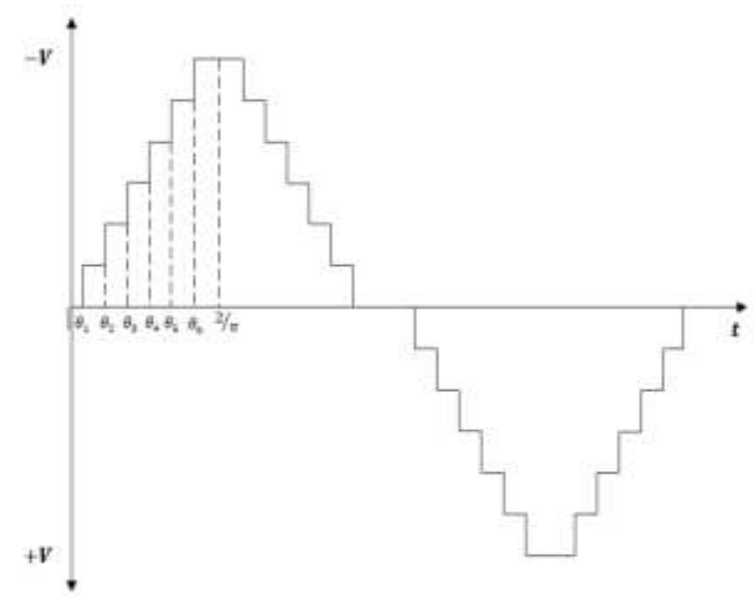

Figure 4. Output waveform voltage of modified 13level CHB-MLI

Table 1. Output voltage switching behaviour for modified thirteen-level M-CHB-MLI

\begin{tabular}{ccccccccccccccccc}
\hline $\mathrm{S}_{1}$ & $\mathrm{~S}_{2}$ & $\mathrm{~S}_{3}$ & $\mathrm{~S}_{4}$ & $\mathrm{~S}_{5}$ & $\mathrm{~S}_{6}$ & $\mathrm{~S}_{7}$ & $\mathrm{~S}_{8}$ & $\mathrm{~S}_{9}$ & $\mathrm{~S}_{10}$ & $\mathrm{~S}_{11}$ & $\mathrm{~S}_{12}$ & $\mathrm{~S}_{13}$ & $\mathrm{~S}_{14}$ & $\mathrm{~S}_{15}$ & $\mathrm{~V}_{\mathrm{o}}$ \\
\hline 1 & 0 & 0 & 1 & 0 & 1 & 0 & 0 & 1 & 0 & 1 & 0 & 0 & 1 & 0 & $\mathrm{~V}_{\mathrm{dc}}$ \\
1 & 0 & 0 & 1 & 0 & 1 & 0 & 0 & 1 & 0 & 0 & 0 & 0 & 1 & 1 & $\mathrm{~V}_{\mathrm{dc}} / 2$ \\
0 & 1 & 1 & 0 & 0 & 0 & 0 & 0 & 1 & 1 & 0 & 0 & 0 & 1 & 1 & $\mathrm{~V}_{\mathrm{dc}} / 3$ \\
0 & 0 & 0 & 1 & 1 & 0 & 0 & 0 & 1 & 1 & 0 & 0 & 0 & 1 & 1 & $\mathrm{~V}_{\mathrm{dc}} / 4$ \\
0 & 0 & 0 & 1 & 1 & 0 & 0 & 0 & 1 & 1 & 0 & 0 & 1 & 1 & 0 & $\mathrm{~V}_{\mathrm{dc}} / 5$ \\
0 & 0 & 0 & 1 & 1 & 0 & 0 & 1 & 1 & 0 & 0 & 0 & 1 & 1 & 0 & $\mathrm{~V}_{\mathrm{dc}} / 6$ & 0 \\
0 & 0 & 1 & 1 & 0 & 0 & 0 & 1 & 1 & 0 & 0 & 0 & 1 & 1 & 0 & 0 & 0 \\
1 & 1 & 0 & 0 & 0 & 1 & 1 & 0 & 0 & 0 & 1 & 1 & 0 & 0 & 0 \\
0 & 1 & 0 & 0 & 1 & 1 & 1 & 0 & 0 & 0 & 1 & 1 & 0 & 0 & 0 & $-\mathrm{V}_{\mathrm{dc}} / 6$ \\
0 & 1 & 0 & 0 & 1 & 0 & 1 & 0 & 0 & 0 & 1 & 1 & 0 & 0 & 0 & $-\mathrm{V}_{\mathrm{dc}} / 5$ \\
0 & 1 & 0 & 0 & 1 & 0 & 1 & 0 & 0 & 1 & 0 & 1 & 0 & 0 & 1 & $-\mathrm{V}_{\mathrm{dc}} / 4$ \\
0 & 1 & 1 & 0 & 0 & 0 & 1 & 0 & 0 & 1 & 0 & 1 & 0 & 0 & 1 & $-\mathrm{V}_{\mathrm{dc}} / 3$ \\
0 & 1 & 1 & 0 & 0 & 0 & 1 & 1 & 0 & 0 & 0 & 1 & 0 & 0 & 1 & $-\mathrm{V}_{\mathrm{dc}} / 2$ \\
0 & 1 & 1 & 0 & 0 & 0 & 1 & 1 & 0 & 0 & 0 & 1 & 1 & 0 & 0 \\
\hline
\end{tabular}

\section{PROPOSED METHOD OF SHE-PWM TECHNIQUE}

A modulation technique is used in this research paper is a selective harmonic elimination SHE-PWM technique which is based on the fundamental switching frequency strategy [17]. In this technique, the fast Fourier series (FFT) equation applied on the staircase waveform of the output voltage must satisfies the best switching angles in order to generate a symmetrical quarter waveform. The FFT expression for $V_{\text {out }}$ can be defined as,

$$
V(t)_{\text {out }}=\sum_{n=1}^{\infty} a_{n} \sin (n \omega t)+b_{n} \cos (n \omega t)
$$

in which all the even order of harmonics is cleared ( $b_{n}$ equals zero) and only the odd harmonics should be presented. Therefore, the odd coefficient $\left(a_{n}\right)$ can be calculated and only the switching angles at the initial quadrant waveform should be calculated. Thus, for the thirteen level MLI six switching angles must be identified and calculated as essential angle at first waveform quadrant $\left(\theta_{1}, \theta_{2}, \theta_{3}, \theta_{4}, \theta_{5}\right.$ and $\left.\theta_{6}\right)$ [17]. The odd coefficient $\left(a_{n}\right)$ can be calculate as below,

$$
a_{n}=\frac{4}{\pi} \int_{0}^{\pi / 2} V \sin (n \theta) d \theta
$$

Therefore, by assuming that the proposed MLI is a symmetrical CHB-MLI, the input supply units must be equal. Then, the stepping output voltage waveform for MLI can be identified by using FFT expansion as,

$$
V(\omega t)=\frac{4 V_{d c}}{n \pi} \sum_{n=1,3,5, . .,}^{\infty}\left[\cos \left(n \theta_{1}\right)+\cos \left(n \theta_{2}\right)+\cos \left(n \theta_{3}\right)+\cos \left(n \theta_{4}\right)+\cos \left(n \theta_{5}\right)+\cos \left(n \theta_{6}\right)\right] \frac{\sin (n \omega t)}{n}
$$


Indeed, odd coefficient $\left(a_{n}\right)$ at fourier series (FFT) equation need to be further analyzed which can be achieved by taking $V(\omega t)$ as a common factor for each equation sides [18]. The finalized odd series coefficients equation for harmonic order components can be defined as,

$$
a_{n}=\frac{4 V_{d c}}{n \pi}\left[\cos \left(n \theta_{1}\right)+\cos \left(n \theta_{2}\right)+\cos \left(n \theta_{3}\right)+\cos \left(n \theta_{4}\right)\right]
$$

Analytically, for each odd harmonic order of the thirteen-level CHB-MLI , the six order can be obtained six as below,

$$
\begin{aligned}
& {\left[\cos \left(\theta_{1}\right)+\cos \left(\theta_{2}\right)+\cos \left(\theta_{3}\right)+\cos \left(\theta_{4}\right)+\cos \left(\theta_{5}\right)+\cos \left(\theta_{6}\right)\right]=\frac{6 \pi M_{i}}{2}} \\
& {\left[\cos \left(3 \theta_{1}\right)+\cos \left(3 \theta_{2}\right)+\cos \left(3 \theta_{3}\right)+\cos \left(3 \theta_{4}\right)+\cos \left(3 \theta_{5}\right)+\cos \left(3 \theta_{6}\right)\right]=0} \\
& {\left[\cos \left(5 \theta_{1}\right)+\cos \left(5 \theta_{2}\right)+\cos \left(5 \theta_{3}\right)+\cos \left(5 \theta_{4}\right)+\cos \left(5 \theta_{5}\right)+\cos \left(5 \theta_{6}\right)\right]=0} \\
& {\left[\cos \left(7 \theta_{1}\right)+\cos \left(7 \theta_{2}\right)+\cos \left(7 \theta_{3}\right)+\cos \left(7 \theta_{4}\right)+\cos \left(7 \theta_{5}\right)+\cos \left(7 \theta_{6}\right)\right]=0} \\
& {\left[\cos \left(9 \theta_{1}\right)+\cos \left(9 \theta_{2}\right)+\cos \left(9 \theta_{3}\right)+\cos \left(9 \theta_{4}\right)+\cos \left(9 \theta_{5}\right)+\cos \left(9 \theta_{6}\right)\right]=0} \\
& {\left[\cos \left(11 \theta_{1}\right)+\cos \left(11 \theta_{2}\right)+\cos \left(11 \theta_{3}\right)+\cos \left(11 \theta_{4}\right)+\cos \left(11 \theta_{5}\right)+\cos \left(11 \theta_{6}\right)\right]=0}
\end{aligned}
$$

The modulation index is defined as $M_{i}=\frac{a_{1}}{l V_{d c}}$, where $l$ is the number of independent DC sources. Actually, this nonlinear transcendental equation cannot be calculated by simple mathematical equation, and virtually need to be carried out with complicated methods such as the iterative approach methods like the N-R, PSO, FFA and ANN techniques $[19,20]$.

\section{ANN PERFORMANCE EVALUATION}

An Artificial Neural Network technique can be defined as a method used to process and arrange the information and determine a desired data based on a principle work of biological nervous system [21]. Nowadays, the ANN technique is considered as a useful and powerful control method in many areas especially in electronic control field. A basic structure model of ANN is formed from number of layers that containing limited number of activation functions which are called as neurons. Each of these layers are interconnected with each other by connection weight in order to control a processing method and each layer also has its own bias parameter which acts as a regulation value [22]. Generally, the ANN is composed of three main layers; input layer, hidden layers and output layer, connected by using weight connection as in Figure 5. The input layer acts as input data holder layer, hidden layers for processing layers and output layer to provide the output data as shown in Figure 6 [23].

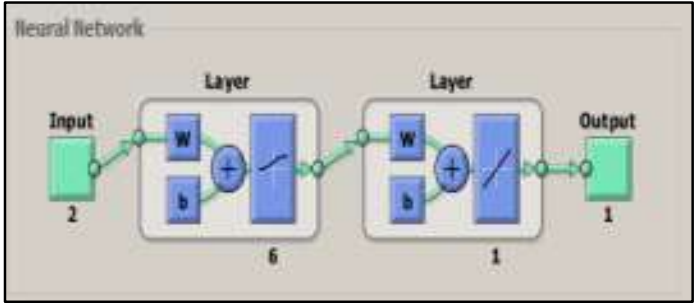

Figure 5. Black diagram for artificial neural network

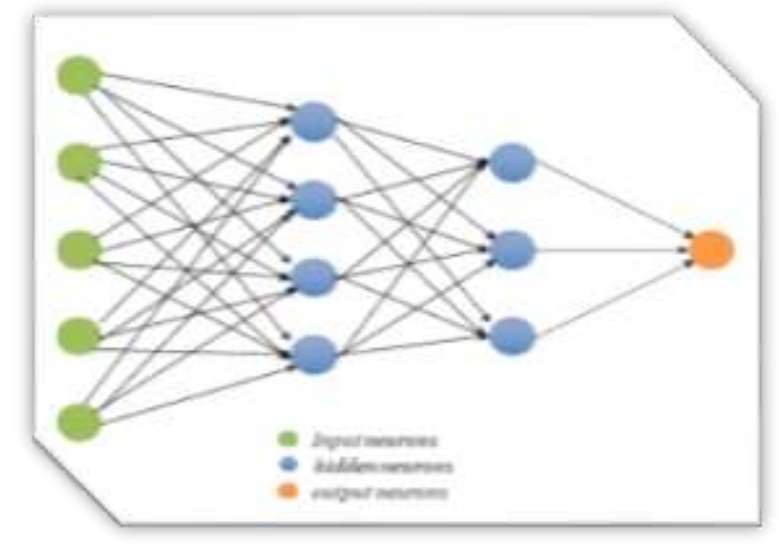

Figure 6. ANNs structure

The ANN can be classified into two main structure based on the feedback unit; the feedback ANN (FBANN) which contains a feedback unit and the feed-forward ANN (FF-ANN) which does not contain a feedback unit. Indeed, any ANN to be established need firstly fed with training data in order to understand and form a 
relationship between the input data and output data to act with faster transient response [24]. In fact, there are a several algorithms that have been emerged as a training method but the most suitable method for this work is the Levenberg-Marquardt algorithm due to its faster training procedure and requires a lesser memory as compared with other methods [25]. By using the ANN as a control system to calculate the nonlinear transcendental equation, results with higher performance is achieved as compared with other studies which used different control methods. That is because of its ability to mapping the fundamental relation between the input and output data during the training process [26].

The first neuron of the output layer is used as an input neuron in order to generate the switching signal for the proposed MCHB-MLI [27]. Then network transfer function can be defined for $i^{\text {th }}$ neuron at $m^{\text {th }}$ layer as follow,

$$
n_{i}^{m}=\sum_{j=1}^{S^{m-1}} W_{i j}^{m} a_{j}^{m-1}+b_{i}^{m}
$$

where $W_{i j}^{m}$ is the weight connections parameter between $j^{\text {th }}$ and $i^{\text {th }}$ neuron at $m^{\text {th }}$ layer and $b_{i}^{m}$ are the bias parameter of $m^{\text {th }}$ layer at $i^{\text {th }}$ neuron. Also $a_{j}^{m}$ is the neuron output function at $m^{\text {th }}$ layer which can be defined as,

$$
a_{i}^{m}=f^{m}\left(n_{i}^{m}\right)
$$

The activation function $(f)$ for the network design in this work is known as a tangent hyperbolic function at the hidden layer which can be defined as,

$$
f^{m}\left(n_{i}^{m}\right)=\frac{2}{1+e^{-2 n_{i}^{m}}}-1
$$

where $f$ at output layer is unity [22].

The harmonic minimization equation using the ANN is described as above. Figure 7 shows the flow chart of the ANN procedure of the harmonic minimization problem and Figure 8 displays the results of optimal switching angles [28].

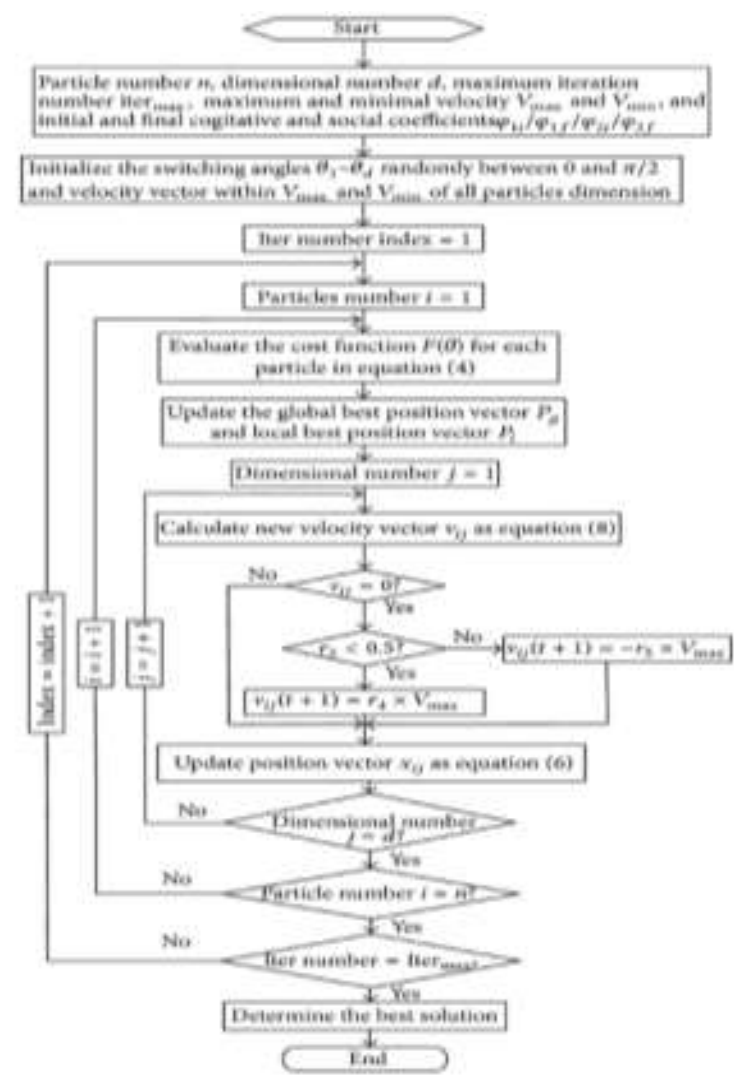

Figure 7. Flow chart of ANN applied to harmonic minimization problem

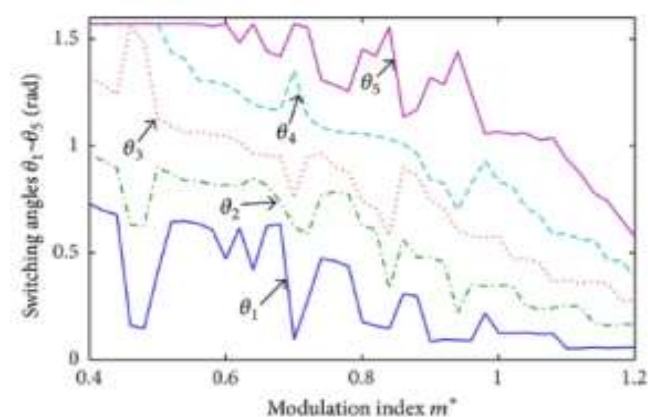

Figure 8. Calculated switching angles $\theta_{1}$ $\theta_{2}, \theta_{3}$, and $\theta_{4}$ 
The result of training performance for ANN consists of two hidden neurons have been training is displayed in Figure 9(a), and Figure 9(b) illustrates the gradient mean squared error and validation of ANN performance of the modified 13-level CHB-MLI which is used to update and correct both the weight and bias values of the network system. Furthermore, the validation is used to monitor the error through the training procedure.

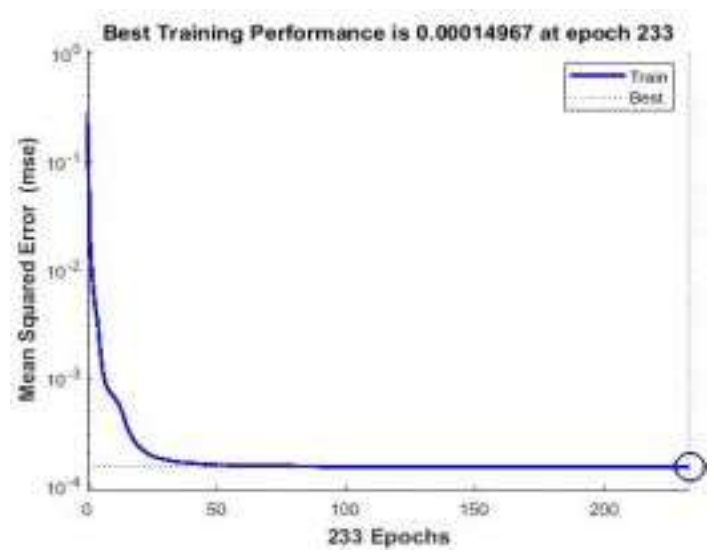

(a)

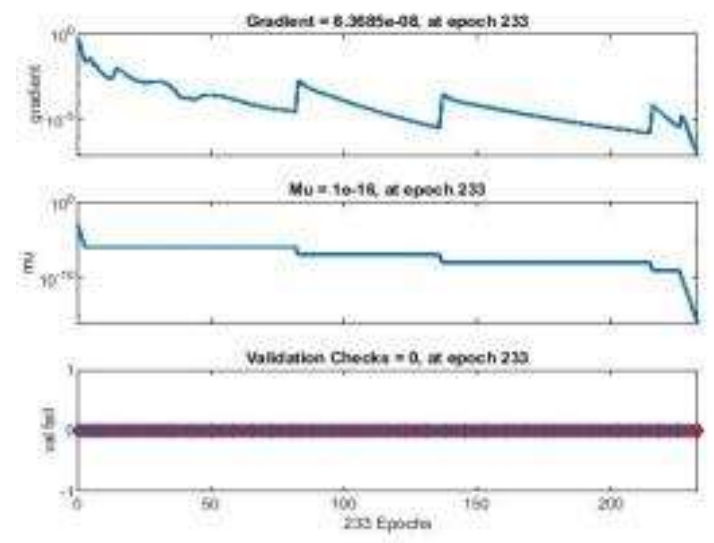

(b)

Figure 9. ANN training performance with 2 hidden neurons

\section{MATLAB SIMULATION OF MODIFIED THIRTEEN LEVEL CHB-MLI}

Using MATLAB simulation tools, the proposed modified CHB-MLI to output a thirteen-level waveform is designed. The system is composed of three modified cells connected in series where each cell contains a pulse generator unit as a switching control system as shown in Figure 10 and Figure 11.

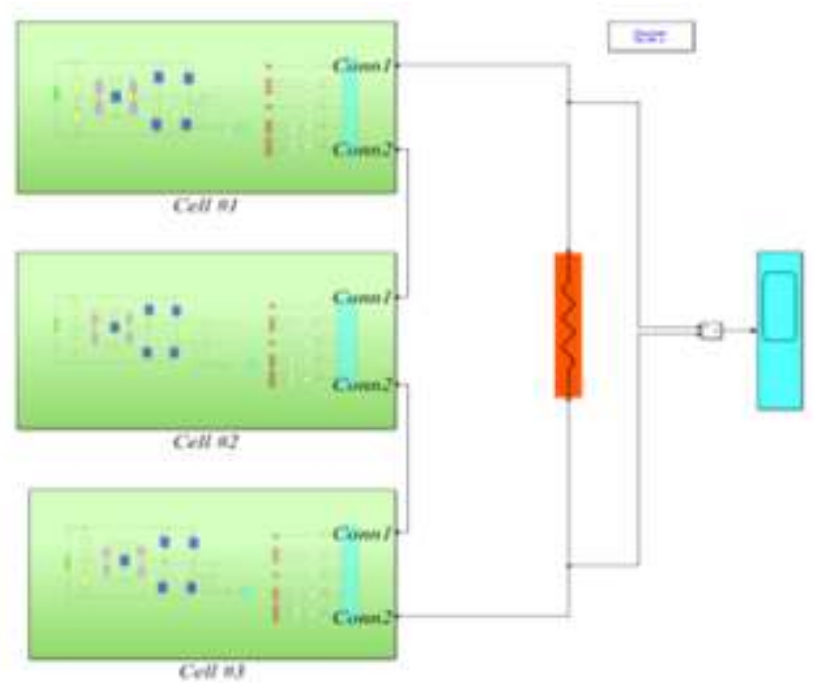

Figure 10. Matlab simulation model for modified 13-level CHB-MLI 


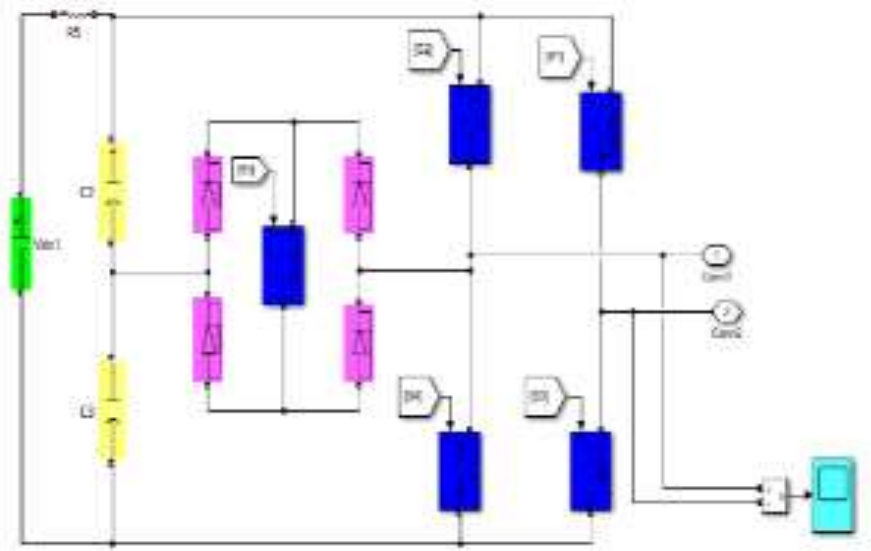

CZUL NOFI STRUCTURE

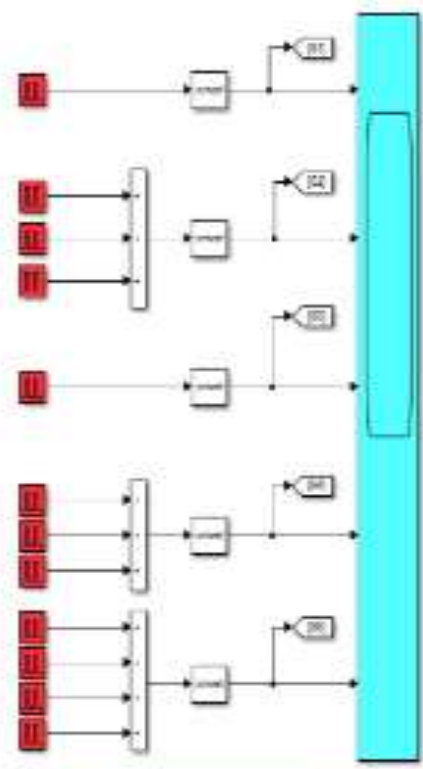

CONTROL SISTEN FOR NOA

Figure 11. Matlab simulation model of the the modified five-level cells of CHB-MLI

\section{SIMULATION RESULTS FOR OPTIMIZATION OF A SINGLE-PHASE THIRTEEN LEVEL MODIFIED CHB-MLI WITH $M_{i}=0.9$ BASED ON ANN TECHNIQUE}

By using the MATLAB software coding, the artificial neural network (ANN) component of a singlephase waveform system is created in order to generate six initial switching angles used to control a thirteen-level modified CHB-MLI. The three separated input DC sources are set equal to $300 \mathrm{~V}$ and switching frequency of $2500 \mathrm{~Hz}$ is applied. At the load side, the system produces an AC waveform to feed a single-phase load of resistor $R=80 \Omega$, inductor $L=35 \mathrm{mH}$ and capacitor $C=50 \mu \mathrm{F}$. The results of the initial six switching angles using the ANN method at $M_{i}=0.9$ are $\theta_{1}=4.53^{\circ}, \theta_{2}=13.48^{\circ}, \theta_{3}=24.13^{\circ}, \theta_{4}=34.63^{\circ}, \theta_{5}=45.79^{\circ}$ and $\theta_{6}=62.31^{\circ}$. The duration time of each cycle at the output waveform is equal to 0.2. Figure 12 and Figure 13 displays the prediction data and original data of the THD during testing time, and the training performance of the ANN testing angles set respectively.

Figure 14 shows the control timing of the pules generators of real switching time for each switch in the $S_{1}, S_{2}, S_{3}, S_{4}$ and $S_{5}$ system by using the ANN optimization switching angles for the three cells model. Cell one consists of , cell two consists $0 S_{6}, S_{7}, S_{8}, S_{9}$ and $S_{10}$ f and cell three consists of $S_{11}, S_{12}, S_{13}, S_{14}$ and $S_{15}$ as shown in (a), (b) and (c) respectively. The 13-level output waveform is shown in Figure 15. For both current and voltage, the THD of 5.16\% and $0.62 \%$ are achieved as shown in Figure 16 and Figure 17.

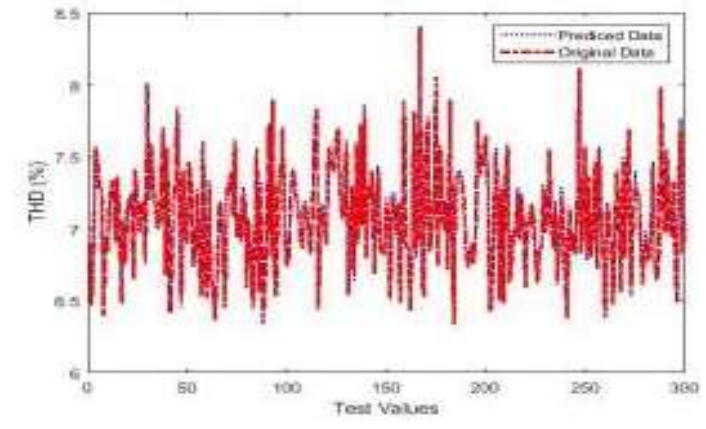

Figure12. Predicted data and original data for THD

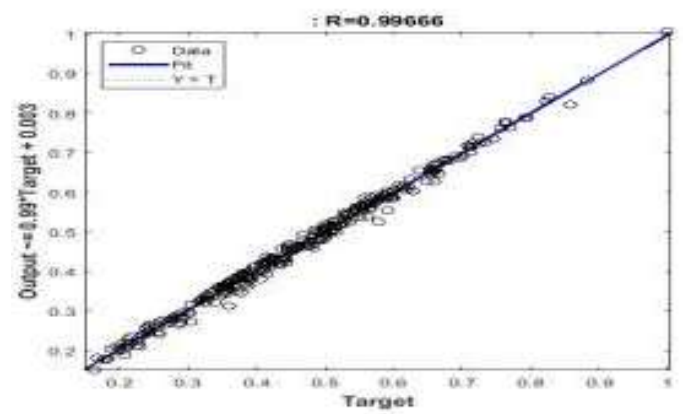

Figure 13. Testing angles training performance using ANN 


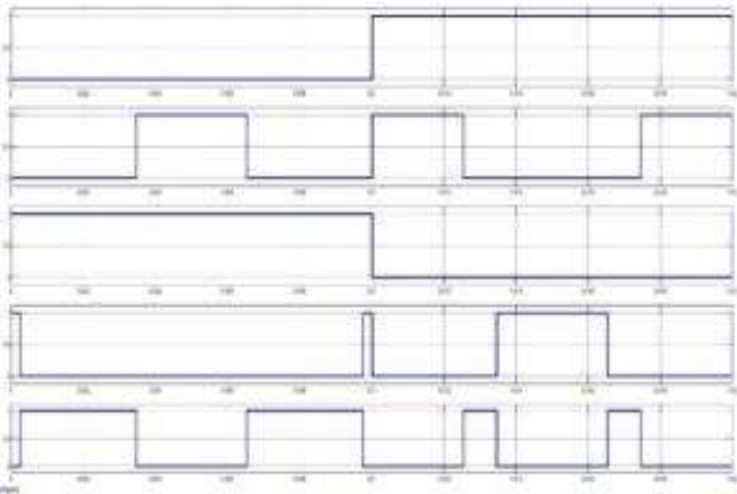

(a) time switching for $S_{1}, S_{2}, S_{3}, S_{4}$ and $S_{5}$

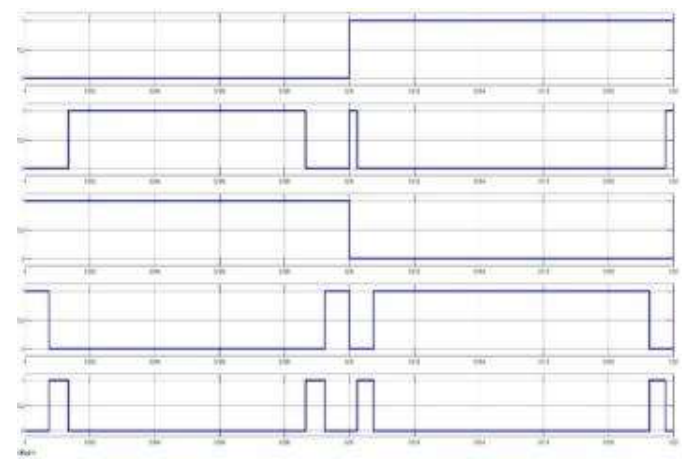

(c) time switching for $S_{11}, S_{12}, S_{13}, S_{14}$ and $S_{15}$

Figure 14. Time switching diagram of 13-level CHB-MLI using ANN technique

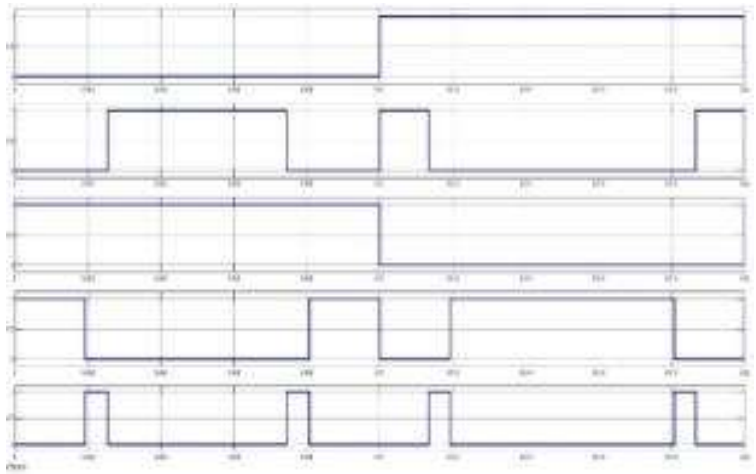

(b) time switching for $S_{6}, S_{7}, S_{8}, S_{9}$ and $S_{10}$

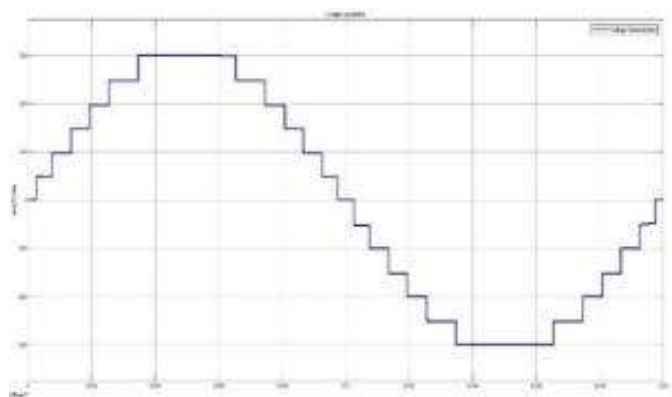

Figure 15. Simulation results of the output voltage waveform for 13-level modified CHB-MLI

Previously, a single-phase five-level and nine-level modified CHB-MLI using ANN technique are proposed. Table 2 displays the comparison of switching angles and the different of THD in voltage and current of them with the thirteen-level modified CHB-MLI.

Table 2. Comparison between 5-levels, 9-level and 13-level of modified CHB-MLI based on proposed ANN

\begin{tabular}{cccccccccc} 
& \multicolumn{10}{c}{ technique at $M_{i}=0.9$} \\
\hline N-level & MI & $\theta_{1}$ & $\theta_{2}$ & $\theta_{3}$ & $\theta_{4}$ & $\theta_{5}$ & $\theta_{6}$ & $\mathrm{THD}_{\mathrm{V}}$ & $\mathrm{THD}_{\mathrm{A}}$ \\
\hline 5-level & 0.9 & 13.41 & 41.93 & - & - & - & - & $14.48 \%$ & $2.05 \%$ \\
9-level & 0.9 & 7.871 & 20.05 & 44.12 & 52.83 & - & - & $7.46 \%$ & $1.38 \%$ \\
13-level & 0.9 & 4.53 & 13.48 & 24.13 & 34.63 & 45.79 & 62.31 & $5.16 \%$ & $0.62 \%$
\end{tabular}

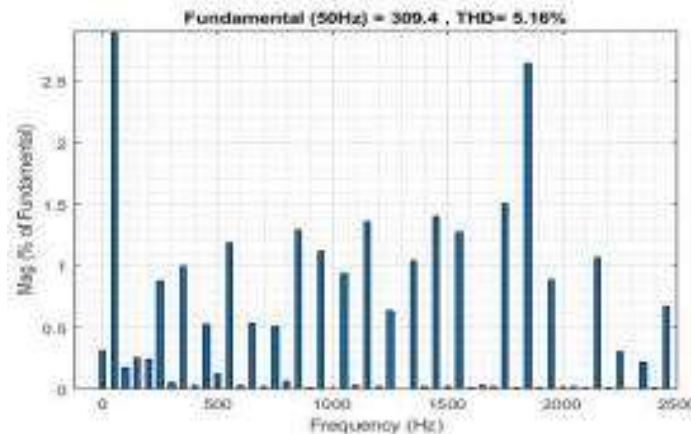

Figure 16. Simulation results of harmonic spectrum for output voltage waveform using ANN technique

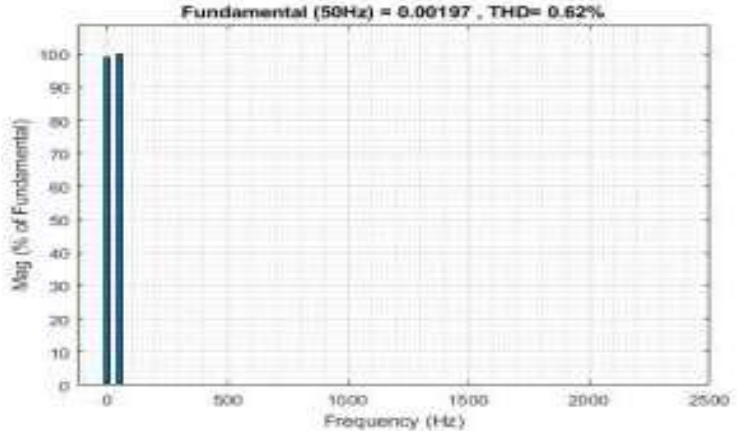

Figure 17. Simulation result of harmonic spectrum for output current waveform using ANN technique 


\section{EXPERIMENTAL RESULTS OF A SINGLE-PHASE MODIFIED CHB-MLI}

The hardware installation circuit of the 13-level modified CHB-MLI is made up by cascading three modified cells, where each one includes five switching semiconductors devices (IGBTs-IHW30N90T) as shown in Figure 18. The operation ability of the IGBT can reach up to $100 \mathrm{kHz}$ for switching frequency. The peak current supply at normal temperature of $25^{\circ}$ is $60 \mathrm{~A}$, which reduces to $30 \mathrm{~A}$ when the temperature reaches up to $100^{\circ}$. Meanwhile the voltage break down of the IGBT devices is $900 \mathrm{~V}$. Coding for the controller is stored using a digital signal processor platform based on DSPTMS320F2812 hardware.

Experiment is conducted to verify the results obtained in the simulation. Figure 19(a) to (c) shows the time switching signal for all the three cells. Figure 20 shows the resulted output voltage waveform. The output voltage harmonic spectrum with THD of 5.3\% is shown in Figure 21. This verifies the result of 5.16\% from the simulation.

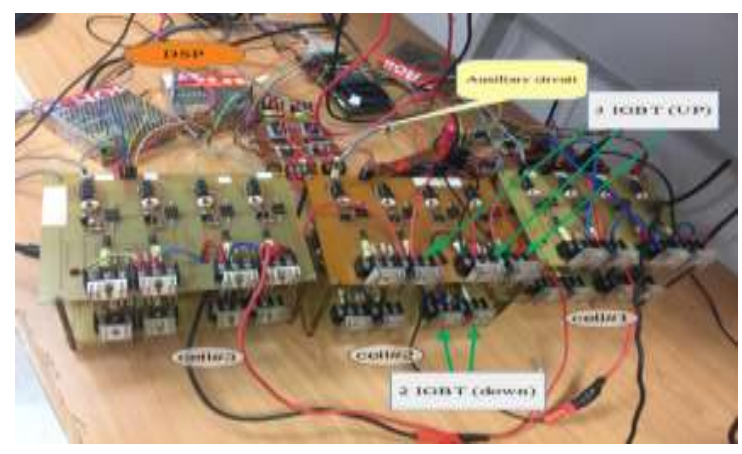

Figure 18. Hardware circuit of a single-phase of 13-levels modified CHB-ML

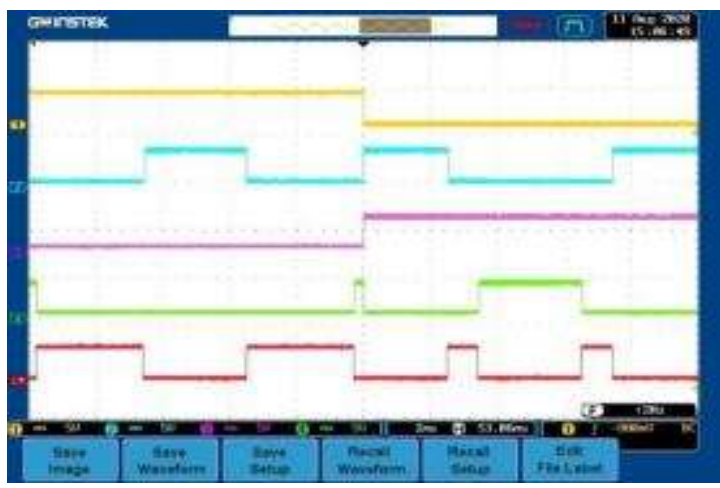

Figure 19(a). Timing diagram of cell one comprising switches $\mathrm{S}_{1}, \mathrm{~S}_{2}, \mathrm{~S}_{3}, \mathrm{~S}_{4}$ and $\mathrm{S}_{5}$

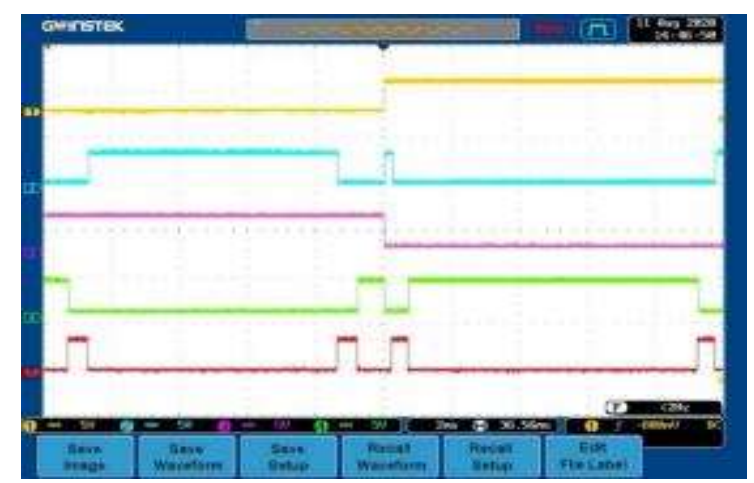

Figure 19(c). Timing diagram of cell three comprising switches $\mathrm{S}_{11}, \mathrm{~S}_{12}, \mathrm{~S}_{13}, \mathrm{~S}_{14}$ and $\mathrm{S}_{5}$

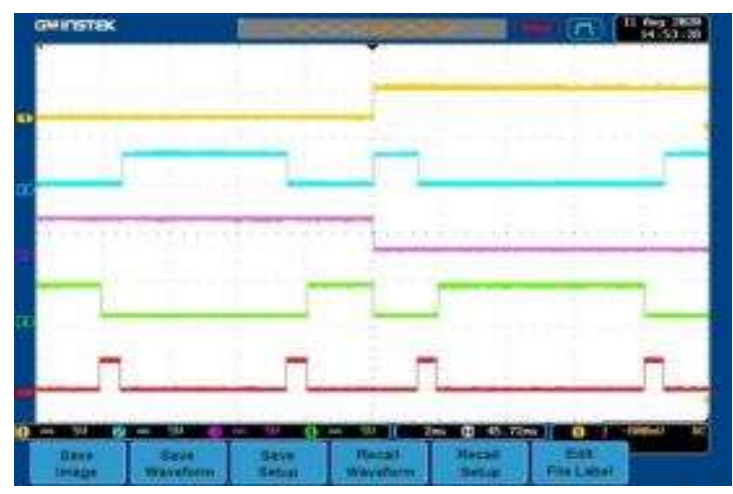

Figure 19(b). Timing diagram of cell two comprising switches $\mathrm{S}_{6}, \mathrm{~S}_{7}, \mathrm{~S}_{8}, \mathrm{~S}_{9}$ and $\mathrm{S}_{10}$

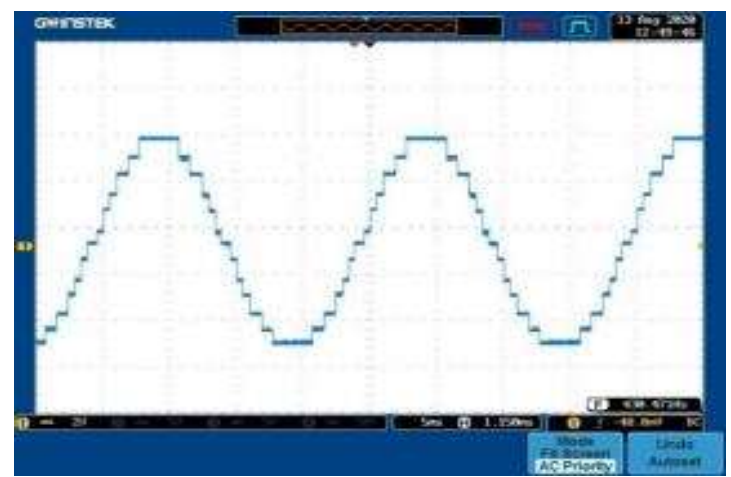

Figure 20. Output voltage waveform of a 13-level modified CHB-MLI with $M_{i}=0.949$ using ANN 


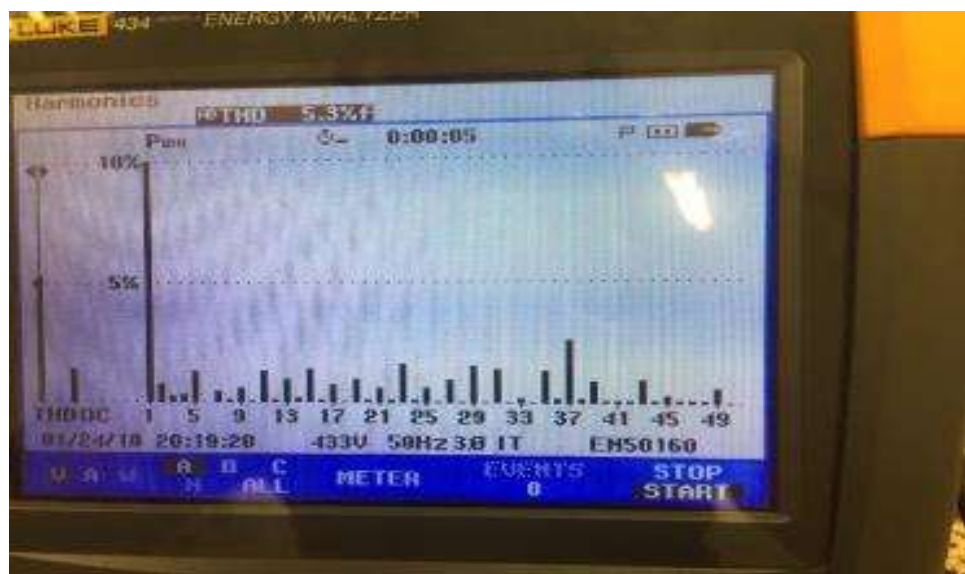

Figure 21. Harmonic spectrum of output voltage waveform of 13-level modified CHB-MLI using ANN technique

\section{CONCLUSIONS}

The ANN technique is proposed in this research paper as optimization method for the thirteen-level modified CHB-MLI which able to reduce the THD of the output voltage and current waveform. System modelling and simulation works are conducted by using the MATLAB Simulink software in order to investigate the designed parameters. Comparison of the resulted THD for the output waveform of the 13-level with the previously carried out results for the 5-level and 9-level CHB-MLI shows a better THD performance as the level is increased. The results obtained from the hardware experiment shows a good agreement with the simulation of THD 5.16\% for the output voltage. In brief, the effectiveness of the proposed ANN technique as optimization method is satisfactorily shown. In future, a thourough THD performance comparison with other optimization methods such as the N-R, PSO and FFA is to be conducted.

\section{REFERENCES}

[1] J. M. Carrasco et al., "Power-electronic systems for the grid integration of renewable energy sources: A survey," IEEE Trans. Ind. Electron., vol. 53, no. 4, pp. 1002-1016, 2006.

[2] G. Nageswara Rao, P. Sangameswara Raju, and K. Chandra Sekhar, "Harmonic elimination of cascaded H-bridge multilevel inverter based active power filter controlled by intelligent techniques," Int. J. Electr. Power Energy Syst., vol. 61, no. 5, pp. 56-63, 2014.

[3] D. A. Khatir, "A Universal Selective Harmonics Elimination Method for High Power Inverters," The Ohio State University, 2012

[4] Prasadarao K, V. S., Joshi M., V., "Grid interconnection of PV system using symmetric and asymmetric MLI topology," International Journal of Power Electronics and Drive Systems, vol. 9, no. 4, pp. 1616-1623, 2018.

[5] Arikesh, A., \& Parvathy, A. K., "Modular multilevel inverter for renewable energy applications," International Journal of Electrical and Computer Engineering (IJECE), vol. 10, no. 1, pp. 1-14, 2020.

[6] J. Venkataramanaiah, Y. Suresh, and A. K. Panda, "A review on symmetric, asymmetric, hybrid and single DC sources based multilevel inverter topologies," Renew. Sustain. Energy Rev., vol. 76, no. March, pp. 788-812, 2017.

[7] M. Rasheed, R. Omar, M. Sulaiman, W. Abd Halim, and M. M.A. Alakkad Majeda, "Artificial Intelligence Technique to Real-Time Based on Selective Harmonic Elimination in Modified Multilevel Inverter," J. Eng. Appl. Sci., vol. 14, no. 24, pp. 9692-9700, 2019.

[8] Shanono, I. H., Abdullah, N. R. H., \& Muhammad, A., "Five-level single source voltage converter controlled using selective harmonic elimination," Indonesian Journal of Electrical Engineering and Computer Science (IJEECS), vol. 12, no. 3, pp. 924-932, 2018.

[9] Dash, S. K., Nayak, B., \& Sahu, J. B., "Selective harmonic elimination of an eleven level inverter using whale optimization technique," International Journal of Power Electronics and Drive Systems (IJPEDS), vol. 9, no. 4, pp. 1944-1957, 2018.

[10] B. Alamri, A. Sallama, and M. Darwish, "Optimum SHE for cascaded H-bridge multilevel inverters using: NR-GAPSO, comparative study," IET Semin. Dig., vol. 2015, no. CP654, pp. 1-10, 2015.

[11] Abdul-Adheem, W. R. (2019). An enhanced particle swarm optimization algorithm. International Journal of Electrical and Computer Engineering, 9(6), 4904-4907. doi:10.11591/ijece.v9i6.pp4904-4907.

[12] W. A. H. Mohammed Rasheed, Rosli Omar, Moataz M.A. Alakkad, Marizan Sulaiman, "Analysis of a Switching Angle Calculation by ANN for nine level inverter Apply into Experimental Case Study with elimination of lower and higher order harmonics," Indones. J. Electr. Eng. Comput. Sci., vol. 20, no. 3, pp. 31-42, 2020.

[13] Krismadinata, N. A. Rahim, H. W. Ping, and J. Selvaraj, "Elimination of Harmonics in Photovoltaic Seven-level Inverter with Newton-raphson Optimization," Procedia Environ. Sci., vol. 17, no. 4, pp. 519-528, 2013.

Real-time switching thirteen-level modified CHB-multilevel inverter using ... (Moataz. M.A. Alakkad) 
[14] R. Jose, L. Jih-Sheng, and P. Fangzheng, "Multilevel inverters: A survey of topologies, controls, and applications," IEEE Trans. Ind. Electron., vol. 49, no. 2, pp. 724-738, 2002.

[15] N. Prabaharan and K. Palanisamy, "Analysis of cascaded H-bridge multilevel inverter configuration with double level circuit,” IET Power Electron., vol. 10, no. 9, pp. 1023-1033, 2017.

[16] S. Sudha Letha, T. Thakur, and J. Kumar, "Harmonic elimination of a photo-voltaic based cascaded H-bridge multilevel inverter using PSO (particle swarm optimization) for induction motor drive," Energy, vol. 107, pp. 335-346, 2016.

[17] A. Parkash and S. L. S. Chatterji, "Harmonics Elimination in Cascade Multilevel Inverters Using Newton- Raphson and Genetic Algorithm," Int. J. Sci. Res. Dev., vol. 2, no. 5, pp. 236-239, 2014.

[18] M. Sabahi, A. R. M. Iranaq, K. M. Bahrami, K. M. Bahrami, and M. B. B. Sharifian, "Harmonics elimination in a multilevel inverter with unequal DC sources using genetic algorithm," 2011 Int. Conf. Electr. Mach. Syst. ICEMS 2011, 2011.

[19] A. Parkash, S. . Shimi, and S. Chatterji, "Harmonics Reduction in Cascade H-Bridge Multilevel Inverters Using GA and PSO," Int. J. Eng. Trends Technol., vol. 12, no. 9, pp. 453-465, 2014.

[20] C. Y. H'ng, B. Ismail, M. Isa, and M. N. K. H. Rohani, "Selective harmonic elimination pulse width modulation for five-level cascaded inverter," J. Telecommun. Electron. Comput. Eng., vol. 10, no. 1-14, pp. 67-71, 2018.

[21] R. Kumar, M. Misra, and A. K. Sarje, “Applications of Artificial Neural Networks in Power Electronics," Proc. - Int. Conf. Comput. Intell. Multimed. Appl. ICCIMA 2007, vol. 4, pp. 275-282, 2008.

[22] W. A. H. and M. M. A. Mohammad Rasheed, Rosli Omar, Marizan Sulaiman, "Artificial Intelligence Technique to Real-Time Based on Selective Harmonic Elimination in Modified Multilevel Inverter," J. Eng. Appl. Sci., vol. 14, no. 24, p. 9, 2019.

[23] R. Kumar, S. P. Singh, and B. Kumar, "Performance Comparison of SVPWM and ANN based SVPWM Technique for Power Quality Improvement," Procedia Comput. Sci., vol. 93, pp. 1024-1037, 2016.

[24] Gaur, P. and Singh, P. "Optimization Techniques for Harmonics Minimization in Cascaded Hybrid Multilevel Converters: a Review,” Int. J. Res. Eng. Technol., vol. 4, no. 3, pp. 188-193, 2015.

[25] R. Taleb and A. Meroufel, "Control of asymmetrical multilevel inverter using artificial neural network," Elektron. ir Elektrotechnika, no. 8, pp. 69-74, 2009.

[26] R. Taleb, A. Meroufel, and P. Wira, "Harmonic elimination control of an inverter based on an artificial neural network strategy," IFAC Proc. Vol., vol. 42, no. 19, pp. 25-30, 2009.

[27] M. Mahesh, K Kranthi, and P. Singh, "Artificial Neural Network Based Closed Loop Control of Multilevel Inverter," Int. J. Mod. Trends Sci. Technol., no. 2, 2016.

[28] W. A. H. Mohammed Rasheed, Moataz M.A. Alakkad, Rosli Omar, Marizan Sulaiman, "Enhance the Accuracy of Control Algorithm for Multilevel Inverter Based on Artificial Neural Network," Indonesian Journal of Electrical Engineering and Computer Science (IJEECS), vol. 20, no. 3, pp. 31-41, 2020. 